\title{
Studi Awal: Persentase Penetasan dan Performa Pertumbuhan Benih Ikan Clown (Amphiprion percula)
}

\author{
Handrina Susanti ${ }^{1}$, Akhmad Taufiq Mukti ${ }^{2 *}$ \\ ${ }^{1}$ Program Studi Akuakultur, Fakultas Perikanan dan Kelautan, Universitas Airlanga, Kampus \\ C Unair, Jl. Mulyorejo, Surabaya, Indonesia 60115 \\ ${ }^{2}$ Departemen Manajemen Kesehatan Ikan dan Budidaya Perairan, Fakultas Perikanan dan \\ Kelautan, Universitas Airlangga, Kampus C Unair, Jl. Mulyorejo, Surabaya, Indonesia 60115 \\ e-mail: 2akhmad-t-m@fpk.unair.ac.id
}

\begin{abstract}
Abstrak
Permintaan ikan clown (Amphiprion percula) saat ini cukup tinggi, baik untuk pemenuhan pasar dalam negeri dan pengiriman ke luar negeri. Perkembangan kondisi pasar yang menggiurkan tersebut, tentu akan memacu para eksportir untuk mengeksploitasi sumber dialam secara tidak terkendali. Tujuan dari studi ini adalah untuk menghitung persentase penetasan dan performa pertumbuhan benih ikan clown. Studi ini dilaksanakan di Balai Perikanan Budidaya Laut (BPBL) Lombok, Nusa Tenggara Barat. Studi ini menggunakan metode observasi secara langsung pada wadah pembenihan dan pemeliharaan larva ikan clown. Induk ikan clown dipijahkan pada akuarium ukuran 0,4 $m \times 0,3 \mathrm{~m} \times 0,5 \mathrm{~m}$. Jumlah telur yang dihasilkan bervariasi sekitar 403-698 butir/induk dengan persentase fertilisasi dan penetasan, masing-masing sebesar 97,29 dan 82,87\%.. Selanjutnya larva dan benih ikan dipelihara di bak beton dengan ukuran $2 \mathrm{~m} \times 2 \mathrm{~m} \times 1 \mathrm{~m}$. Persentase kelangsungan hidup benih mencapai 98,33\% dan peningkatan bobot tubuh rerata setiap minggu adalah 0,332, 0,343, 0,388, dan 0,421 g. Budidaya ikan clown di darat dengan kelangsungan hidup tinggi dapat mengurangi tingkat eksploitasi ikan clown di alam dan kebutuhan akan ekspor ikan hias dapat terpenuhi.
\end{abstract}

Kata kunci- Amphiprion percula, pembenihan, pembesaran benih, hatching rate, survival rate

\begin{abstract}
Clownfish (Amphiprion percula) demand is currently quite high, both for the fulfillment of the domestic market and overseas shipping. The development of these lucrative market conditions will certainly spur exporters to exploit natural resources uncontrollably. The aim of this study was calculated hatching rate and growth performance of clownfish larvae. This study was conducted at the Mariculture Fisheries Station (MFS) Lombok, Nusa Tenggara Barat. This study was used directly observation method in hatchery and culture containers of clownfish larvae. Clownfish broodstocks were spawned in a aquarium size of $0.4 \mathrm{~m} \times 0.3 \mathrm{~m} \times$
\end{abstract}


Jurnal Biosains Pascasarjana Vol. 22 (2020) pp

(C) (2020) Sekolah Pascasarjana Universitas Airlangga, Indonesia

$0.5 \mathrm{~m}$. The eggs number produced varies around 403 to 698 eggs/fish with fertilization and hatching rates of 97.29 and $82.87 \%$, respectively. Next, larvae and fry were reared in a concrete pond size of $2 m \times 2 m \times 1 \mathrm{~m}$. Survival rate of clownfish fry have reached $98.33 \%$ and increased the average body weight are 0.332, 0.343, 0.388, and $0.421 \mathrm{~g}$ every week, respectively. Cultivation of clownfish in land with high survival can reduce the exploitation level of clownfish in the nature and the need for ornamental fish exports can be met.

Keywords- Amphiprion percula, hatchery, fry cultivation, hatching rate, survival rate 
Jurnal Biosains Pascasarjana Vol. 22 (2020) pp

(C) (2020) Sekolah Pascasarjana Universitas Airlangga, Indonesia

\section{PENDAHULUAN}

Ikan clown (clownfish) termasuk jenis ikan hias akuarium air laut yang mempunyai penggemar cukup banyak. Jenis yang sangat umum dikenal dan telah berhasil ditangkarkan salah satunya yaitu Amphiprion percula dan Amphiprion ocellaris. Ada 34 jenis ikan clown yang telah teridentifikasi dan ditemukan pada perairan `dangkal sampai perairan dalam, serta pada dasar yang berkarang. Secara umum ikan clown mempunyai corak warna dasar dengan kombinasi : merah putih, merah - hitam dan hitam - kuning putih. Corak warna dan variasi kombinasi warna dijadikan sebagai ciri dalam identifikasi jenis ikan clown (Zulfikar dkk, 2018). Ikan clown hidup secara bergerombol dan habitatnya di alam selalu berdampingan atau bersimbiosis dengan anemon laut.

Ikan clown tersebar luas di ekosistem terumbu karang di wilayah tropis dan subtropis mulai dari Indonesia sampai Barat Pasifik: Archipelago Australia Indo termasuk India, Burma, Thailand, Malaysia, Indonesia, Filipina, Nugini, New Britain, Kepulauan Solomon, Vanuatu dan Australia (Madhu, 2012). Burgess (1990) menjelaskan bahwa ikan clown termasuk Famili Pomacentridae dengan genus Amphiprion spesies Amphiprion percula. Clownfish atau ikan badut memiliki ciri warna tubuh jingga (orange), ukuran kecil, gerakan lincah dan termasuk ikan jinak, dihiasi dengan 3 garis putih dengan siluet hitam gelap pada bagian pangkal kepala, tengah-tengah badan dan pangkal ekor serta suka bersembunyi atau berlindung pada anemon. Garis putih di bagian badan mempunyai corak yang berbeda dengan dua garis putih lainnya yaitu sisi luar garis putih dihiasi siluet hitam dengan bagian garis putih lebih beragam bentuknya dan lebih besar dan sisik relatif besar. Pola warna pada ikan ini sering dijadikan dasar pada proses identifikasi, disamping bentuk gigi, kepala dan bentuk tubuh dan warna pada mata Clownfish.

Permintaan ikan clown saat ini cukup tinggi, baik untuk pemenuhan pasar dalam negeri dan pengiriman ke luar negeri dengan negara tujuan pemasaran antara lain Australia, Jepang, Jerman, dan Perancis. Perkembangan kondisi pasar yang menggiurkan tersebut, tentu akan memacu para eksportir untuk mengeksploitasi sumber di alam secara tidak terkendali yang akan menyebabkan keberadaan ikan clown dialam terancam punah. Pemenuhan kebutuhan pasar akan permintaan ikan clown dan mengurangi penangkapan dialam agar tidak terjadi kepunahan pada ikan clown, maka perlu dilakukan penangkaran atau budidaya.

Budidaya ikan clown tidak dapat berkembang pesat apabila benih ikannya hanya mengandalkan dari tangkapan alam. Oleh karena itu, perlu upaya pembenihan dan pemeliharaan larva ikan clown dalam wadah terkontrol. Tujuan dari studi ini adalah untuk menghitung persentase penetasan dan performa pertumbuhan benih ikan clown.

\section{METODE PENELITIAN}

Studi ini dilaksanakan di Balai Perikanan Budidaya Laut (BPBL) Lombok, Nusa Tenggara Barat. Metode yang digunakan pada studi ini adalah observasi secara langsung.

\subsection{Pembenihan Ikan Clown}

Pembenihan ikan diawali dengan pemeliharaan induk dalam akuarium dengan ukuran $0,4 \mathrm{~m} \times 0,3 \mathrm{~m} \times 0,5 \mathrm{~m}$ yang dilengkapi dengan saluran inlet dan 
outlet yang terbuat dari pipa PVC dengan diameter $20 \mathrm{~mm}$. Persiapan akuarium yang dilakukan yaitu penyusutan air yang ada dalam akuarium dengan membuka saluran outlet, pembersihan akuarium di seluruh bagian akuarium termasuk pada bagian pipa inlet dan outlet sampai bersih. Kemudian akuarium dibilas menggunakan air tawar dan dilakukan pemeriksaan apabila terjadi kebocoran atau kerusakan. Selanjutnya akuarium dikeringkan (minimal selama satu hari, agar terhindar dari hama dan penyakit). Akuarium diisi dengan air laut dengan ketinggian mencapai 35-40 cm. Kemudian, sepasang induk ikan clown dimasukkan dan ke dalam akuarium tersebut.

Indukan yang digunakan berasal dari hasil tangkapan di alam. Induk yang baru tiba diaklimatisasi terlebih dahulu dengan cara menempatkan ikan dalam bak fiber dan diberi air mengalir, kemudian dipindahkan ke bak plastik yang berisi air tawar dan obat elbajo untuk menghilangkan berbagai parasit dan bakteri. Selanjutnya induk dikembalikan ke dalam bak pemeliharaan untuk dilakukan penjodohan dengan meletakkan anemone dalam bak fiber tersebut. Setelah 7-12 hari, jika ada sepasang indukan (jantan dan betina) yang menguasai daerah anemone, maka indukan tersebut berjodoh dan siap memijah. Indukan yang berjodoh tersebut akan dipindahkan ke dalam akuarium untuk dipijahkan.

Ukuran induk yang digunakan memiliki panjang total 5-8 cm. Induk yang berukuran lebih kecil (jantan) dipasangkan dengan induk yang berukuran lebih besar (betina). Selain ukuran, ikan jantan biasanya berwarna lebih cerah dan lebih kurus daripada ikan betina. Setiawati dkk. (2012) menyatakan bahwa indukan yang didapatkan dari alam harus dilakukan perendaman dengan air tawar dan erubaju untuk menghilangkan parasit dan bakteri dari ikan tersebut.

Indukan yang telah berjodoh akan melakukan perkawinan dan akan siap memijah. Induk jantan yang akan memijah akan lebih agresif mengejar betina, sedangkan untuk induk betina perutnya buncit, genital papilanya berwarna merah dan kemudian akan berwarna putih dan gerakan renangnya akan naik turun. Setelah terlihat ciri-ciri seperti di atas, maka pada akuarium akan ditambahkan substrat berupa genteng atau keramik yang akan digunakan sebagai substrat oleh ikan clown untuk menempelkan telur. Beberapa hari setelah substrat diletakkan, indukan akan terlihat membersihkan substrat yang akan digunakan untuk menempelkan telurnya.

Pemijahan ikan clown akan terjadi sepanjang tahun dan dalam satu bulan terjadi 3 kali pemijahan dengan produksi telur bisa mencapai 1500 butir bahkan bisa lebih. Indukan yang pertama kali melakukan pemijahan umumnya akan menghasilkan telur 200-500 butir telur. Jumlah telur yang dihasilkan tergantung dari siklus pemijahan dan besar dari indukan yang memijah. Rasio pemijahan ikan clown adalah 1:1 karena sifatnya yang berpasangan.

Setelah telur dikeluarkan dan ditempelkan disubstrat oleh induk betina, maka ikan clown jantan akan mengeluarkan sperma dan mengipasi telurnya agar terbuahi semuanya. Perkembangan telur terjadi selama 7 hari sampai telur akan siap menetas menjadi larva. Penetasan telur dilakukan di bak fiber dengan ukuran $3 \mathrm{~m} \times 1 \mathrm{~m} \times 0,8 \mathrm{~m}$. Telur dalam akuarium akan dipindahkan ke bak fiber bersama dengan induknya untuk ditetaskan dengan metode green water, yaitu menggunakan fitoplankton Nannochloropsis sp. Jumlah telur yang dikeluarkan masing-masing induk, jumlah 
telur terfertilisasi dan menetas selanjutnya dihitung.

\subsection{Pembesaran Larva Ikan Clown}

Setelah menetas, larva ikan clown dipelihara dalam kolam pemeliharan yang terbuat dari beton berukuran $2 \mathrm{~m} \times 2 \mathrm{~m} \times$ $1 \mathrm{~m}$ dengan ketinggian air mencapai 0,5 $\mathrm{m}$. Sebelum digunakan sebagai bak pemeliharaan, bak beton dicuci sampai bersih, disiram menggunakan air tawar dan dikeringkan. Bak beton dilengkapi dengan saluran outlet yang terbuat dari pipa PVC dengan diameter $5 \mathrm{~cm}$ dan saluran inlet berdiameter $20 \mathrm{~mm}$.

Larva ikan clown dipelihara selama 1 bulan. Selama pemeliharaan kolam diberi Nannochloropsis sp. yang bertujuan untuk stabilitas air bak pemeliharaan larva dan sebagai pakan alami bagi zooplankton Rotifer yang akan menjadi pakan bagi larva ikan clown. Pemberian pakan alami pada awal pemeliharaan berguana untuk memicu laju pertumbuhan yang baik dan pakan alami ini juga sesuai dengan bukaan mulut larva. Pemberian pakan alami diberikan selama 30 hari dan pada hari ke20 bisa diberikan pakan tambahan berupa pakan buatan pelet.

Selama pemeliharaan larva atau benih dilakukan seleksi. Seleksi larva atau benih ikan dilakukan untuk mendapatkan benih yang seragam dan sehat. Setelah mendapatkan ukuran ikan yang seragam, ikan direndam pada air tawar dan elbajo untuk menghindari ikan dari serangan penyakit. Benih yang digunakan berukuran $1-1,5 \mathrm{~cm}$ dengan padat tebar setiap kolam 600 ekor/kolam. Penebaran benih dilakukan pada pagi hari untuk menghindari stress pada benih ikan clown.

Selama pemeliharaan ikan clown diberikan pakan buatan berupa pellet. Pakan buatan yang digunakan adalah pakan buatan jepang dengan merek dagang otohime, sedangkan larva ikan diberikan pakan buatan dari tepung ikan dan lebih banyak mengkonsumsi pakan alami. Pemberian pakan untuk benih menggunakan pakan dengan merek yang sama, tetapi ukuran yang berbeda yaitu 250-360 $\mu \mathrm{m}$, untuk pembesaran ukuran 580-910 $\mu \mathrm{m}$ dan untuk indukan menggunakan pakan dengan ukuran 6,5 $\mathrm{mm}$ dan pakan tambahan berupa udang yang dihaluskan dengan ditambahkan vitamin $\mathrm{E}$, hal tersebut bertujuan agar ikan cepat matang gonad (BPBLL, 2015).

Pemberian pakan dilakukan minimal 2 kali dalam sehari yaitu pada pagi dan sore hari. Pakan diberikan dengan perlahan dan hati-hati agar ikan clown tidak stress. Pakan diberikan secara ad libitum.

Pada pemeliharaan larva atau benih, nilai rasio konversi pakan (RKP) dan pertumbuhan benih ikan dihitung. Pengukuran pertumbuhan dilakukan satu kali dalam seminggu untuk mengetahui apakah pakan yang diberikan dapat dicerna dengan baik dan dapat meningkatkan pertumbuhan panjang maupun berat tubuh ikan. Sampling yang dilakukan menggunakan 10 ikan.

Selama pemeliharaan benih ikan clown, kualitas air seperti salinitas, ammonia, oksigen terlatur, dan $\mathrm{pH}$ diukur setiap minggu sekali dengan cara sampel air diambil dan dibawa ke laboratorium untuk dianalisis, sedangkan pengukuran suhu dilakukan secara langsung di kolam pembesaran. Pengukuran suhu menggunakan termometer air raksa, $\mathrm{pH}$ menggunakan $\mathrm{pH}$ meter, salinitas menggunakan refraktometer, oksigen terlarut menggunakan DO meter, dan ammonia menggunakan ammonia test.

\section{HASIL DAN PEMBAHASAN}


Jurnal Biosains Pascasarjana Vol. 22 (2020) pp

(C) (2020) Sekolah Pascasarjana Universitas Airlangga, Indonesia

Hasil pengamatan pembenihan ikan kedua yaitu 0,343 g, pada minggu ketiga clown dapat dilihat pada Tabel 1 .

Tabel 1. Data pemijahan induk ikan clown

\begin{tabular}{cccc}
\hline \multirow{2}{*}{ Induk } & Jumlah telur & Jumlah telur & Telur menetas \\
& (butir) & terbuahi (butir) & (ekor)
\end{tabular}

yaitu $0,388 \mathrm{~g}$, dan pada minggu keempat yaitu $0,421 \mathrm{~g}$. Pengukuran dari minggu pertama sampai minggu keempat terjadi peningkatan pertumbuhan dalam berat. Pertumbuhan panjang juga mengalami peningkatan dari minggu petama sampai

\begin{tabular}{llll} 
A1 & 689 & 674 & 601 \\
A2 & 503 & 496 & 389 \\
A3 & 434 & 401 & 343 \\
A4 & 403 & 396 & 321 \\
A5 & 612 & 602 & 531 \\
A6 & 601 & 591 & 476 \\
A7 & 698 & 679 & 524 \\
\hline
\end{tabular}

Berdasarkan Tabel 1 didapatkan nilai persentase fertilisasi rata-rata setiap induk ikan clown adalah sebesar 97,29\%. Persentase fertilisasi merupakan persentase telur yang terbuahi dari jumlah telur yang dikeluarkan pada proses pemijahan. Nilai persentase fertilisasi tersebut tergolong tinggi.

Nilai persentase penetasan yang didapatkan juga tinggi yaitu rata-rata sebesar 82,87 \%. Sutarjo (2014) menyatakan bahwa persentase penetasan adalah persentase jumlah telur yang menetas dari sejumlah telur yang terfertilisasi. Keberhasilan daya tetas telur yang tinggi dapat dipengaruhi oleh beberapa faktor yang meliputi kualitas telur, kualitas air dan penanganan pada saat penetasan.

Setelah melakukan sampling pada pembesaran ikan clown didapatkan ratarata pertumbuhannya pada minggu pertama adalah $0,332 \mathrm{~g}$, pada minggu minggu keempat yaitu pada minggu pertama panjang rata-rata yang didapatkan adalah $1,48 \mathrm{~cm}$, pada minggu kedua yaitu $1,50 \mathrm{~cm}$, pada minggu ketiga yaitu 1,82 $\mathrm{cm}$ dan pada minggu keempat yaitu 2,14 $\mathrm{cm}$. Garif pertumbuhan berat dan panjang pada ikan clown dapat dilihat pada Gambar 1.

Peningkatan pertumbuhan yang terjadi pada ikan clown menandakan bahwa pakan yang diberikan dapat dicerna dengan baik dan menjadi energi untuk pertumbuhan ikan.

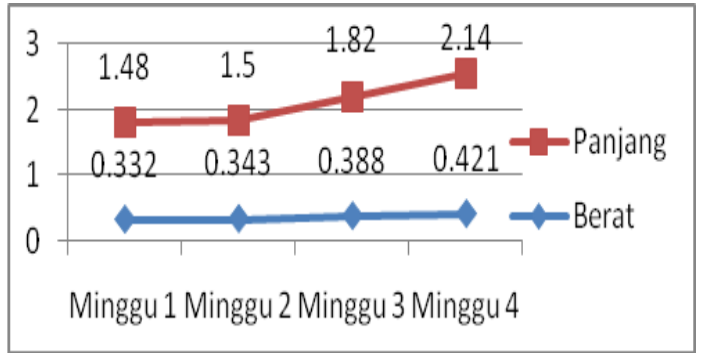

Gambar 1. Grafik pertambahan panjang dan berat tubuh ikan clown selama pemeliharaan 4 minggu

Selama pemeliharaan benih ikan clown, nilai konversi pakan yang didapat adalah 0,35. Nilai konversi pakan merupakan suatu ukuran yang menyatakan rasio jumlah pakan yang dibutuhkan untuk menghasilkan satu kilogram ikan kultur (Sawhney et al., 2010). Pada dunia akuakultur, penghematan pakan menjadi prioritas utama karena dapat menekan biaya produksi.

Pemeliharaan ikan clown dari larva sampai tahap pembesaran benih memiliki nilai tingkat kelangsungan hidup yang JBP Vol. 22, No. 1, Juni 2020-Handrina Susanti 
tinggi, yaitu mencapai 98,33\%. Hal ini dikarenakan selama pemeliharaan, kesehatan ikan dan keadaan lingkungan selalu diperhatikan dan dijaga seperti akan kebutuhan oksigen dan kadar ammonia dalam air pemeliharaan. Berdasarkan penelitian yang dilakukan Diansyah dkk (2016) menyatakan bahwa persentase kelangsungan hidup ikan clown dapat mencapai $100 \%$ dikarenakan prosedur pemeliharaan yang tepat dan rendahnya mortalitas ikan. Pemanenan dilakukan pada benih yang mencapai panjang mulai dari $1 \mathrm{~cm}$ sampai ukuran $6 \mathrm{~cm}$ tergantung dari pembeli atau pemesanan yang menginginkan ukuran berapa.

Selama pemeliharaan benih ikan clown, kualitas air terukur antara lain adalah oksigen terlarut berkisar antara 7,0$8,4 \mathrm{mg} / \mathrm{L}$, suhu sekitar $28-30{ }^{\circ} \mathrm{C}$, salinitas sekitar 25-26 ppt, pH berkisar antara 7,57,8 , dan ammonia kurang dari $0,01 \mathrm{mg} / \mathrm{L}$. Hasil pengukuran diatas dapat diketahui bahwa semua parameter dalam keadaan normal untuk pertumbuhan ikan clown (A. percula). Setiawati dan Hutapea (2011) menyatakan bahwa kondisi perairan yang cocok untuk kegiatan budidaya ikan clown adalah memiliki nilai parameter derajat keasaman optimum pada kisaran 6.7-8.6, oksigen terlarut lebih dari $6 \mathrm{mg} / \mathrm{l}$, dan suhu berkisar antara $27-32{ }^{\circ} \mathrm{C}$. Salinitas yang baik untuk pertumbuhan ikan hias clown adalah berkisar antara 25-40 ppt, sedangkan ammonia tidak melebihi batas yang dianjurkan atau tetap berada dalam batas normal maksimal $0,01 \mathrm{mg} / \mathrm{l}$.

Kualitas air memegang peranan penting pada budidaya ikan. Kualitas air perlu diukur karena kelayakan suatu perairan subagai lingkungan hidup ditentukan oleh sifat fisik dan kimia air seperti suhu, salinitas, derajat keasaman, osigen terlarut, karbonsilaksida bebas, alkalinitas perairan, kandungan amoniak dan beberapa parameter lainnya (Faisyal dkk., 2016).

Boyd (1990) menyatakan bahwa suhu maksimum untuk pertumbuhan ikan adalah $25-30{ }^{\circ} \mathrm{C}$, tetapi pada daerah tropis ikan tidak dapat tumbuh bagus pada suhu dibawah $26{ }^{\circ} \mathrm{C}$.

\section{KESIMPULAN DAN SARAN}

Studi awal pembenihan ikan clown menunjukkan persentase fertilisasi dan penetasan telur ikan clown sangat tinggi. Pertumbuhan dan kelangsungan hidup benih ikan clown cukup tinggi dengan rasio konversi pakan yang rendah. Perlu studi lebih lanjut terkait diet pakan yang sesuai untuk ikan clown hingga siap panen, sehingga dapat menekan biaya produksi.

\section{UCAPAN TERIMAKASIH}

Penulis menyampaikan rasa hormat dan ucapan terima kasih kepada Kepala dan staf BPBL Lombok, Sekotong Lombok Barat, NTB yang telah memberikan fasilitas dan bahan untuk pelaksanaan studi ini.

\section{DAFTAR PUSTAKA}

Allen, G.R. 1997. Marine Fishes of South East Asia. Kaleidoscope Print and Prepress Periplus Edition, Perth, Western Australia.

Ari,W. Kadek, Suci Antoro dan Valentina, 2009. Perbaikan Produksi Benih Amphiprion ocellaris dengan Aplikasi Berbagai Fitoplankton. Seminar IndoAqua, Manado.

Burgess,W. 1990. ATLAS Of Marine Aquakultur Fishes. T.F.H. Publication. USA.

Boyd CE. 1990. Water Quality in Ponds for Aquaculture. Alabama: Birmingham Publishing Co. 
Jurnal Biosains Pascasarjana Vol. 22 (2020) pp

(C) (2020) Sekolah Pascasarjana Universitas Airlangga, Indonesia

Dunn, D.F. 2004. Para Clownfish Anemon Laut: (Coelenterata:Actiniaria) dan Anemon Laut Lainnya Simbiosis Dengan Ikan. Philosophical Society,71-115.

Faisyal,Y., S. Rejeki dan L.L Widowati. 2016. Pengaruh Padat Tebar Terhadap Pertumbuhan dan Kelulusan Hidup Ikan Bandeng (Chanos chanos) di Keramba Jaring Apung di Perairan Terabrasi Desa Kaliwlingi Kabupaten Brebes. Journal Of Aquakultur Management and

Technology,5(1):155-161.

Fautin, D.G. 2007 Anemon Ikan dan

Anemon Laut Tuan Mereka:

Panduan Untuk Aquarists dan

Penyelam. Museum Australia

Barat.

Gusrina. 2008. Budidaya Ikan Jilid 1. Direktorat Pembinaan Sekolah Menengah Kejuruan. Departemen Pendidikan Nasional.

Kayu, E. M. 2004. Koleksi Ikan Terumbu Karang Untuk Akuarium: Perdagangan Global, Isu-isu Konservasi dan Strategi Manajemen. Konservasi Laut Masyarakat, Inggris. 80pp.

Malcolm, B. 2004. Cage Akuakultur. Fishing News Book. Ttd, Farnham, Surey, England.376pp.

Mebs, D. 2009. Kimia Biologi Hubungan Mutualistik Anemon Laut Dengan Ikan dan Udang-Udangan. Journal Toxicon.

Megawati, R.A., M. Arief dan M.A Alamsjah. 2012. Pemberian Pakan Dengan Kadar Serat Kasar Yang Berbeda Terhadap Daya Cerna Pakan Pada Ikan Berlambung dan Tidak Berlambung. Jurnal Ilmiah Perikanan dan Kelautan,4(2):187192.
Myers R., 1999. Miconesian Reff Fish: A Field Guide for Divers and Aquarist, Barigada: Teritory of Guam: Coral Graphics.

Nugroho, S. 2008. Analisis Finansial Usaha Ikan Hias Air Tawar Heru Fish Farm di Desa Kotabatu, Kecamatan Ciomas, Kabupaten Bogor, Jawa Barat. Fakultas Perikanan Dan Ilmu Kelautan. Institut Pertanian Bogor. Bogor. 133 hlm.

Raco, J.R dan C.R Semiawan. 2010. Metode Penelitian Kualitatif. Grasido:Cikarang.

Sabilah, F. 2018. Teknik Pemijahan Ikan Badut (Amphiprion ocellaris) di Balai Besar Perikanan Budidaya Laut, Lampung. PKL Fakultas Perikanan dan Kelautan, Universitas Airlangga. 79 hal.

Sari, I.P dan A.Manan.2012. Pola Pertumbuhan Nannochloropsis oculata Pada Kultur Skala Laboraturiu,Intermediet dan Massal. Jurnal Ilmiah Perikanan dan Kelautan,4(2):123-128.

Setiawati, K.M dan J.H Hutapeaaa. 2011. Pemeliharaan Benih Ikan Klon (Amphiprion ocellaris) Dengan Sistem Pengelolaan Air Yang Berbeda. Jurnal Riset Akuakultur,6(2):243-253.

Setiawati,K.M., Gunawan dan J.H Hutapea. 2012. Biologi Reproduksi Induk Klon Hitam (Amphiprion percula) Di Hatchery. Jurnal Ilmu dan Teknologi Kelautan Tropis, 4 (2) : 182-190.

Setiawati,K.M., Gunawan dan J.H Hutapea. 2016. Pemeliharaan Larva Ikan Klon (Amphiprion percula) Dengan Pakan Alami yang Berbeda. Jurnal Riset Akuakultur, 11 (1) : 67-73. 
Jurnal Biosains Pascasarjana Vol. 22 (2020) pp

(C) (2020) Sekolah Pascasarjana Universitas Airlangga, Indonesia

Sugiyono. 2010. Metode Penelitian Kuantitatif dan Kualitatif. R\&D Jakarta: CV Alfabeta.277hal.

Suharti, S.R. 1990. Mengenal Kehidupan Ikan Anemon (Pomancentridae). Oseana, 15 (4): 135-145.

Suryana. 2010. Buku Ajar Metodelogi Penelitian Model Praktis Peenelitian Kuantitatif dan Kualitatif. Universitas Pendidikan Indonesia.

Suryabrata, S. 2002. Metodelogi Penelitian. Rajawali. Jakarta:Edisi III.

Tulasi, D. 2006. Cash Flow Ratios Analysis sebagai Metode Pengukuran Kinerja Keuangan Perusahaan. Manajemen Usahawan Indonesia (Oktober). hal 48-54.

Wanbitz,C., et.,al. 2003. Dari Samudera ke Akuarium. Cambridge, Inggris, UNPED-WCMC:64.

Ziemann, D. A. 2003. Potensi Untuk Pemulihan Populasi Ikan Hias Laut Melalui Siaran Pembenihan. Aquarium Ilmu dan Konservasi, 3:107-117.

Zulfikar., E. Marzuki dan Erlangga. 2018. Pengaruh Warna Wadah Terhadap Pertumbuhan dan Kelangsungan Hidup Ikan Badut (Amphiprion ocellaris). Acta Aquatica: Aquatic Sciences Journal, 5,(2) :88-92. 